\title{
Antioxidant properties of extracts and SPE fractions from Annona muricata leaves
}

\author{
${ }^{1}$ Hashim, N.A., ${ }^{1,2^{*}}$ Ya'akob, H., ${ }^{2}$ Rosdi, M.N.M., ${ }^{1}$ Zainol, N.A., ${ }^{1}$ Husin, F., ${ }^{2}$ Soib, H.H. and \\ ${ }^{2}$ Norhisham, N.F. \\ ${ }^{1}$ Institute of Bioproduct Development, School of Chemical and Energy Engineering, Faculty of Engineering, \\ Universiti Teknologi Malaysia, 81310, Skudai, Johor, Malaysia \\ ${ }^{2}$ Department of Bioprocess and Polymer Engineering, School of Chemical and Energy Engineering, \\ Universiti Teknologi Malaysia, 81310, Skudai, Johor, Malaysia
}

\begin{abstract}
Article history:
Received: 23 October 2019

Received in revised form: 8 March 2020

Accepted: 12 March 2020

Available Online: 15 April 2020
\end{abstract}

\section{Keywords:}

Annona muricata,

Extractions,

Solid phase extraction (SPE), Antioxidant,

1,1-Diphenyl-2-

picrylhydrazyl (DPPH)

DOI:

https://doi.org/10.26656/fr.2017.4(S2).S02

\begin{abstract}
Annona muricata L. (Magnoliales: Annonaceae) is a tropical plant species known for its edible fruit and well known for the medicinal value. In this study, the antioxidant properties of A. muricata leaves is evaluated for different extracts and fractions. The airdried leaves of $A$. muricata leaves were successively extracted with $n$-hexane and methanol. The methanolic crude extract was further semi-purified by utilizing solid-phase extraction (SPE) in a mixture of mobile phase aqueous: methanol to methanol and resulted in four semi-purified fractions (ALM 1 - ALM 4). Antioxidant properties of extracts and fractions were evaluated by free radical scavenging activity against 1,1-Diphenyl-2picrylhydrazyl (DPPH) radicals comparing with standard ascorbic acid, quercetin, and catechin. Results indicated that methanolic extracts showed exceptionally higher radical scavenging activity compared with $n$-hexane crude extract with $\mathrm{IC}_{50} 44.21 \mu \mathrm{g} / \mathrm{mL}$ and $302.41 \mu \mathrm{g} / \mathrm{mL}$, respectively. Meanwhile, fractions ALM 2 (aqueous: methanol; 50: 50) exhibited the highest scavenging activity with the $\mathrm{IC}_{50}$ of $12.46 \mu \mathrm{g} / \mathrm{mL}$ followed by ALM 1 (aqueous: methanol; 80: 20) with $51.44 \mu \mathrm{g} / \mathrm{mL}$, ALM 3 (aqueous: methanol; 20: 80) with $54.39 \mu \mathrm{g} / \mathrm{mL}$ and ALM $4(100 \%$ methanol) with $89.02 \mu \mathrm{g} / \mathrm{mL}$, respectively. In conclusion, ALM 2 could be potentially applied as a natural antioxidant agent in both food, nutraceuticals or pharmaceuticals fields for health promotion. However, ALM 2 has to be further purified to study the constituents which possibly condensed mainly with phenolic and flavonoids that known to possess the highest antioxidant effects.
\end{abstract}

\section{Introduction}

Oxidant and free radicals participate as both toxic and beneficial to the body (Adewole and CaxtonMartins, 2006). As a result, free radical production continuously occurs in all cells as part of normal cellular function. However, excess of free radical production might play a role in many diseases. Current lifestyle and environment accumulate an overproduction of Reactive Oxygen Species (ROS) and free radicals, such as superoxide anion radical $\left(\mathrm{O}_{2}^{\circ}\right)$, hydrogen peroxide $\left(\mathrm{H}_{2} \mathrm{O}_{2}\right)$ and hydroxyl radical $(\mathrm{OH} \bullet)$ and are introduced into the body as by-products in normal metabolic functions. These molecules/radicals are immense factors in cellular injury such as cardiovascular diseases, cancer and others which accounted for a major portion of deaths today (Alafiatayo et al., 2014; Sumczynski et al., 2015). There are several techniques available in assessing antioxidant capacity which has been used extensively to plant extracts, such as the most common method which is DPPH free radical scavenging assay (Gerber and Williams, 2002), Trolox equivalent antioxidant capacity (TEAC) assays (Miller et al., 2000), total flavonoid contents assay (Moghadamtousi et al., 2015), and the oxygen radical absorbance capacity (ORAC) assay (Pala and Gurkan, 2008). Malaysia's rainforest encompasses more than 2000 plant species which have been reported to possess various medicinal values. Besides, some of these species are also being utilized in food, beverage, flavor and, fragrance industries. Therefore, traditional plant species have a good prospect not only for the traditional medicinal industries but also for the country's pharmaceutical industry as a whole (Princemail et al., 2014).

Annona muricata L. (Magnoliales: Annonaceae) ( $A$. 
muricata) is a Malaysia tropical plant species known for its edible fruit and well known for the medicinal value. It is an undersized, deciduous commonly known locally as Durian Belanda (soursop) or Graviola belongs to custard apple family and roundish canopy-like tree. The height of this fruit-bearing tree is measured to be in the range between 5 and $8 \mathrm{~m}$ (Qayum et al., 2014). Fruits were consumed as a beverage and help digestion. The seed extracts are used to kill external parasites, head lice, and worms (Taylor, 2005). The phytoconstituents that are naturally present in the plant exhibit disease preventive properties such as annonaceous acetogenins, lactones, and isoquinoline, alkaloids are some of bioactive compounds present in the A. muricata leaves. Hence, this study was designed to evaluate the antioxidant activity and validate the therapeutic efficacy of $A$. muricata fresh leaf extract and its fractions.

\section{Materials and methods}

\subsection{Sample collection and authentication}

Fresh leaves of $A$. muricata were collected at Pontian Kechil, in the city of Pontian [coordinates: $1^{\circ} 31^{\prime} 20.2^{\prime \prime} \mathrm{N}$ $\left.103^{\circ} 22^{\prime} 56.3^{\prime \prime E}\right]$, Johor, Malaysia during April 2018. The identity of the plant was identified and authenticated by Dr. Shamsul Khamis from Pusat Pengajian Sains Sekitaran dan Sumber Alam, Fakulti Sains dan Teknologi, Universiti Kebangsaan Malaysia (UKM), Malaysia, and a voucher specimen has been deposited in the Herbarium of UKM under the collection number SK 2293/13.

\subsection{Chemicals and reagents}

Ascorbic acid (AA), catechin and quercetin were purchased from Goodrich Chemical Enterprise (GCE) while 2,2-diphenyl-1-picrylhydrazyl (DPPH) was purchased from Fluka. The absorbance data for this assay were recorded by Epoch microplate spectrophotometer. All solvents were of analytical grade purchased from Merck.

\subsection{Samples preparation and extraction}

The leaves of $A$. muricata were washed with water and cut into small pieces, drying was done at room temperature for two days, and the dried leaves were powdered. Equal amounts $(1.9 \mathrm{~kg})$ of powdered leaves were successively extracted with $n$-hexane $(1 \mathrm{~L}$ every $500 \mathrm{~g}$, three times successively in $48 \mathrm{hrs}$ ) followed by $\mathrm{MeOH}(1 \mathrm{~L}$ every $500 \mathrm{~g}$, three times successively in 48 hours). The extracts were then concentrated using rotary evaporator and kept at $-20^{\circ} \mathrm{C}$ until used.
2.4 SPE fractionation of the methanolic extracts of Annona muricata

The methanolic leaves extracts of A. muricata were fractionated using Solid-phase extraction (SPE) by referring to the method from (Husin et al., 2019). SPE was performed by using Strata ${ }^{\mathrm{TM}} \mathrm{C} 18$ cartridges $(10 \mathrm{~g} / 60$ $\mathrm{mL})$. The cartridge was first conditioned with $50 \mathrm{~mL}$ of absolute methanol to activate the sorbent and then followed by $100 \mathrm{~mL}$ equilibrium using deionized distilled (DI) water. The crude extract $(2.0 \mathrm{~g})$ was dissolved in 3 $\mathrm{mL}$ of methanol and an addition of $7 \mathrm{~mL}$ DI water and filtered through a $0.22 \mu \mathrm{m}$ syringe filter. Crude extract of $10 \mathrm{~mL}$ was loaded into the SPE column and left in the sorbent matrix for a while. The SPE was performed in gradient elution of methanol-water mixture. Methanolwater mixture was used to Sampling of fraction 1 was collected by eluting $200 \mathrm{~mL}$ of $20 \%$ methanol followed by $50 \%, 80 \%$ and $100 \%$ methanol for fractions 2,3 and 4 , respectively, to collect different polarity of fraction (Soib et al., 2019). All the crude extracts and fractions were tested for antioxidant activity.

\subsection{Antioxidant activity using the 1,1-diphenyl-2- picrylhydrazyl (DPPH) method}

The free radical scavenging activity (RSA) was measured by the DPPH method as described by Miller et al., with minor modification (Tegeli et al., 2006). Different concentrations of the extracts $(3.175,6.25,125$, 250 , and $500 \mu \mathrm{g} / \mathrm{mL}$ ) were used. A volume of $2.5 \mathrm{~mL}$ of $0.04 \%$ DPPH solution was mixed with $0.5 \mathrm{~mL}$ of all the concentrations of both extracts separately. After $30 \mathrm{~min}$ incubation at room temperature in the dark, the absorbance was read at $517 \mathrm{~nm}$ in triplicates for each concentration. Ascorbic acid (AA), Quercetin (QU) and catechin (CA) were used as the positive control.

The percent inhibition of free radical formation was calculated as follows:

$$
\mathrm{I} \%=\left[\left(\mathrm{A}_{\text {blank }}-\mathrm{A}_{\text {sample }}\right) / \mathrm{A}_{\text {blank }}\right] \times 100
$$

Where $A_{\text {blank }}$ is the absorbance value of the control reaction (containing all reagents except the test compound) and $\mathrm{A}_{\text {sample }}$ is the absorbance values of the test compounds. The sample concentration that provides $50 \%$ inhibition $\left(\mathrm{IC}_{50}\right)$ was calculated by plotting inhibition percentages against concentrations of the sample. All tests were carried out in triplicate and $\mathrm{IC}_{50}$ values were reported as logarithmic values of triplicate.

\subsection{Statistical analysis}

The assays were performed in triplicate and the results was expressed as the mean values with standard deviations (SD) by using Microsoft office Excel 2007. 
One-way analysis of variance (ANOVA) followed by Tukey's honestly significant difference (HSD) post hoc test $(\mathrm{p}<0.05)$ (significant differences) was measured by using SPSS version 21.0 (IBM corporation, New York, U.S.A).

\section{Results}

3.1 Quantification of antioxidant activity using the DPPH method

Figure 1 shows an increase in the inhibition of DPPH radical due to the scavenging ability of crude extracts and fractions of $A$. muricata. There was a direct positive relationship between antioxidant activity and the increasing concentration of the extracts and fractions. There was ultimately a higher antioxidant power registered by the methanol extracts as compared to the $n$ hexane extracts $(p<0.05)$ as represented by the calculated $\mathrm{IC}_{50}$ values of $44.21 \mu \mathrm{g} / \mathrm{mL}$ and $302.41 \mu \mathrm{g} /$ $\mathrm{mL}$ respectively.

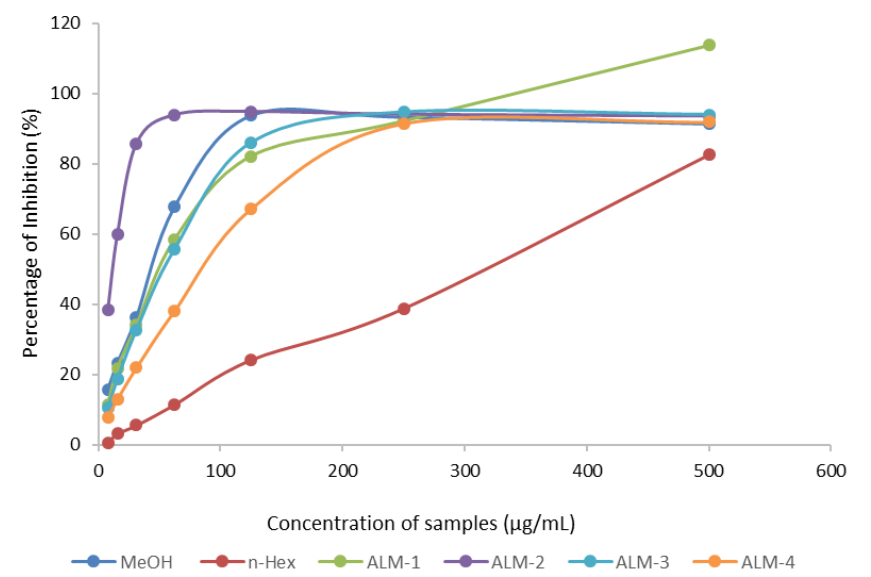

Figure 1. DPPH free radical scavenging activity of $A$. muricata extracts and fractions
The antioxidant activities of each of the four fractions isolated from the methanolic leaves extracts of A. muricata by SPE fractionation were also determined. The percentage radical scavenging assay on DPPH of each of the fractions exceeding $50 \%$ was at $125 \mu \mathrm{g} / \mathrm{mL}$, therefore the percent inhibition only at this concentration and their IC50 were tabulated in Table 1. The highest activity was recorded in fraction ALM-2 and the lowest activity was registered by fraction ALM-4. The percentage inhibition by the fractions were as follows: negative control (0\%), ALM-1 (82.23\%), ALM-2 (94.94\%), ALM-3 (86.03\%), ALM-4 (67.18\%), quercetin (96.34\%), catechin (96.37\%) and ascorbic acid $(96.78 \%)$. The results showed relatively good antioxidant activity recorded by most of the fractions.

\section{Discussion}

The air-dried leaves of $A$. muricata leaves were successively extracted with methanol and $n$-hexane to see whether the active compounds were in a polar or non -polar group. From the DPPH free radical scavenging assessment (RSA), the methanolic crude extract showed a good scavenging activity as compared to the $n$-hexane leaves extract of $A$. muricata, this revealed that the phenolics compounds were higher in the methanol leaves extracts than in the $n$-hexane leaves extracts. Consequently, the fractionation was performed in a mixture of mobile phase aqueous: methanol to investigate the effect of polarity of the solvent on the compounds isolated towards the antioxidant capacity. The weak scavenging activity showed by the $n$-hexane extracts, however, could be explained by the presence of non-polar compounds that have no or less ability to act as a free radical scavenger.

Table 1. Scavenging activity of extracts and fractions of $A$. muricata

\begin{tabular}{|c|c|c|c|}
\hline Sample & Plant Parts & Percentage Inhibition at $125 \mu \mathrm{g} / \mathrm{mL}(\mathrm{I} \%)$ & $\mathrm{DPPH}, \mathrm{IC}_{50}(\mu \mathrm{g} / \mathrm{mL})$ \\
\hline \multicolumn{4}{|l|}{ Crude Extracts } \\
\hline n-Hexane & $\mathrm{ALH}$ & $24.23 \pm 0.6^{\mathrm{a}}$ & $302.41 \pm 0.43^{\mathrm{g}}$ \\
\hline $\mathrm{MeOH}$ & ALM & $93.89 \pm 0.2^{\mathrm{e}}$ & $44.21 \pm 0.03^{\mathrm{c}}$ \\
\hline \multicolumn{4}{|l|}{ Fractions } \\
\hline ALM-1 & & $82.23 \pm 0.3^{\mathrm{c}}$ & $51.44 \pm 0.48^{\mathrm{d}}$ \\
\hline ALM-2 & & $94.94 \pm 0.8^{\mathrm{ef}}$ & $12.46 \pm 0.06^{\mathrm{b}}$ \\
\hline ALM-3 & & $86.03 \pm 0.2^{\mathrm{d}}$ & $54.39 \pm 0.89^{\mathrm{e}}$ \\
\hline ALM-4 & & $67.18 \pm 0.1^{\mathrm{b}}$ & $89.02 \pm .37^{\mathrm{f}}$ \\
\hline \multicolumn{4}{|c|}{ Positive Control } \\
\hline Ascorbic acid & & $96.78 \pm 0.3^{f}$ & $0.33 \pm 0.01^{\mathrm{a}}$ \\
\hline Catechin & & $96.37 \pm 0.7^{\mathrm{ef}}$ & $0.31 \pm 0.01^{\mathrm{a}}$ \\
\hline Quercetin & & $96.34 \pm 0.9^{\mathrm{ef}}$ & $0.39 \pm 0.02^{\mathrm{a}}$ \\
\hline
\end{tabular}

Data represents mean $\pm \mathrm{SD}$ of three independent experiments performed in triplicate; ND: Not determined; A. muricata, ALH: $\mathrm{n}$ Hex Leaves, ALM: MeOH Leaves. Mean values were significantly different $(\mathrm{p}<0.05)$. Mean values in each column with the same letter are not significantly different $(p<0.05)$ by the Tukey's test. 
Although at similar concentrations the extracts may not be competitively strong antioxidants compared to the positive controls, it is likely to point out that the samples assayed in this study were crude extracts, while the standard controls are usually very purified compounds. Nevertheless, all the fractions showed relatively good antioxidant activity with more than $50 \%$ inhibition at 125 $\mu \mathrm{g} / \mathrm{mL}$ concentration as showed in Figure 1 . Interestingly, the fraction ALM-2 possessed the highest antioxidant activity when compared to the other fractions and the crude extract. The lowest antioxidant activity was observed in the fraction ALM-4 when $100 \%$ methanol was used, which is a less polar solvent when compared with aqueous: methanol mixture. These results suggested that polar compounds were successfully separated in the SPE fractionation. This result was also aligned with the previous study that showed good activity in the fraction rather than the crude extract (Soib et al., 2019). However, ALM 2 has to be further purified to study the constituents which possibly condensed mainly with phenolic and flavonoids that known to possess the highest antioxidant effects.

In general, however, the relatively strong antioxidant activity makes this plant effective in managing oxidative stress-related diseases; and this could be the reason why it is used in traditional medicine to manage such diseases where the water extracts are mostly applied ( $\mathrm{Yu}$ et al., 2007). These results also provide a possible lead towards future studies and development of pharmaceutical products with antioxidant properties by targeting the fractions showing the highest activity.

\section{Conclusion}

In summary, this study demonstrated that the methanolic extract of $A$. muricata showed exceptionally higher radical scavenging activity compared with $n$ hexane extract, and purification procedures yielded fraction (ALM 2) with better antioxidant activity than the crude extract. This fraction could be potentially applied as a natural antioxidant agent in both food, nutraceuticals or pharmaceuticals fields for health promotion. However, ALM 2 has to be further purified to study the chemical constituters which possessed the antioxidant activity.

\section{Conflict of interest}

The authors declare no conflict of interest.

\section{Acknowledgements}

This work was financially supported by research funding GUP- Q.J130000.2546.18H84 under Universiti Teknologi Malaysia (UTM), Skudai, Malaysia. We also thank UTM for hosting the Institute for research purposes, and partly funding the research respectively. We also thank Assoc. Prof. Dr. Shajarahtunnur Jamil, Department of Chemistry from Faculty of Science, UTM for her professional advice.

\section{References}

Adewole, S.O. and Caxton-Martins, E.A. (2006). Morphological changes and hypoglycemic effects of Annona muricata linn. (Annonaceae) leaf aqueous extract on pancreatic $\beta$-cells of streptozotocin-treated diabetic rats. African Journal of Biomedical Research, 9(3). https://doi.org/10.4314/ ajbr.v9i3.48903

Alafiatayo, A.A., Ahmad, S. and Maziah, M. (2014). Total Antioxidant Capacity, Total Phenolic Compounds and the Effects of Solvent Concentration on Flavonoid content in Curcuma longa and Curcuma xanthorhhiza Rhizomes. Medicinal Aromatic Plants, 3, 2.

Gerber, R. and Williams, M. (Eds.). (2002). Geography, Culture and Education., p: 62. The Netherlands: Kluwer Academic Publisher. https:// doi.org/10.1007/978-94-017-1679-6

Husin, F., Ya'akob, H., Rashid, S.N.A., Shahar, S. and Soib, H.H. (2019). Cytotoxicity study and antioxidant activity of crude extracts and SPE fractions from Carica papaya leaves. Biocatalysis and Agricultural Biotechnology, 19, 101130. https:// doi.org/10.1016/j.bcab.2019.101130

Miller, H.E., Rigelhof, F., Marquat, L., Prakash, A. and Kanter, M. (2000). Antioxidant Content of Whole Grain Breakfast Cereals, Fruits and Vegetables. Journal of American College Nutrition, 19(Suppl. 3: Whole Grains and Health), 312-319. https:// doi.org/10.1080/07315724.2000.10718966

Moghadamtousi, S.Z., Fadaeinasab, M., Nikzad, S., Mohan, G., Ali, H.M. and Kadir, H.A. (2015). Annona muricata (Annonaceae): A Review of Its Traditional Uses, Isolated Acetogenins and Biological Activities. International Journal of Molecular Sciences, 16(7), 5625-15658. https:// doi.org/10.3390/ijms160715625

Pala, F.S. and Gurkan, H. (2008). The Role of Free Radicals in Ethiopathogenesis of Diseases. Advance Molecular Biology, 1, 1-9.

Princemail, J., Ricour, C., Defrraigne, J.O. and Petermans, J. (2014). Oxidative Stress, Antioxidants and the Ageing Process. Reveue Medicale de Liege, 69(5-6), 270-275.

Qayum, M., Zua-ul-Haq, M., Kaleem, W.A., Ahmad,S., Calani, L., Mazzeo, T. and Pellergini, N. (2014). 
Antioxidant Potential of Impatients bicolour Royle and Zizypus oxyphylla Edgew. Pakistan Journal of Botanical, 46(5), 1725-1729.

Soib, H.H., Yaakob, H., Sarmidi, M.R. and Rosdi, M.N.M. (2019). Fractionation of aqueous extract of Ficus deltoidea var. Kunstleri's leaves using solid phase extraction method for anticancer activity on du145 cell line. Malaysian Journal of Analytical Sciences, 23(3), 534-54.

Sumczynski, D., Bubelova, S., Snyed, J., Erb-Weber, S. and Mleck, J. (2015). Total Phenolics, Flavonoids, Antioxidant Capacity, Crude Fibre and Digestibility in non-Traditional Wheat Flakes and Muesli. Food Chemistry, 174, 319-325. https://doi.org/10.1016/ j.foodchem.2014.11.065

Taylor, L. (2005). Technical Data Report for Graviola (Annona muricata)., p. 56. Austin, Texas, USA: Sage Press.

Tegeli, V., Karpe, P. and Vikas, K. (2006). Importance of Free Radical and Antioxidant in Human Health. International Journal of Pharmaceutical, Chemical and Biological Sciences, 4, 1038-1050.

Yu, K., Zhao, M., Yang, B., Zhao, Q. and Jiang, Y. (2007). Phenolics from hull of Garcinia mangostana Fruit and their Antioxidant Activities. Food Chemistry, 104(1), 176-181. https://doi.org/10.1016/ j.foodchem.2006.11.018 